Defraeye T., Cronjé P., Verboven P., Opara U.L., Nicolai B. (2015), Exploring ambient loading of citrus fruit into reefer containers for cooling during marine transport using computational fluid dynamics, Postharvest Biology and Technology 108, 91-101.

http://dx.doi.org/10.1016/j.postharvbio.2015.06.004

\title{
Exploring ambient loading of citrus fruit into reefer containers for cooling during marine transport using
}

\section{computational fluid dynamics}

Thijs Defraeye ${ }^{\mathrm{a}, \mathrm{b}, \mathrm{c}}{ }^{*}$, Paul Cronjé ${ }^{\mathrm{d}}$, Pieter Verboven ${ }^{\mathrm{a}}$, Umezuruike Linus Opara e,f, Bart Nicolai ${ }^{\mathrm{a}, \mathrm{g}}$

${ }^{a}$ MeBioS, Department of Biosystems, KU Leuven, Willem de Croylaan 42, 3001 Heverlee, Belgium

${ }^{b}$ Laboratory for Building Science and Technology, Swiss Federal Laboratories for Materials Testing and Research

(Empa), Überlandstrasse 129, 8600 Dübendorf, Switzerland

${ }^{c}$ Chair of Building Physics, Swiss Federal Institute of Technology Zurich (ETHZ), Wolfgang-Pauli-Strasse 15, 8093

Zürich, Switzerland

${ }^{d}$ Citrus Research International, Department of Horticultural Sciences, Stellenbosch University, Stellenbosch 7602,

South Africa

e South African Research Chair in Postharvest Technology, Department of Horticultural Sciences, Stellenbosch

University, Stellenbosch 7602, South Africa

${ }^{f}$ South African Research Chair in Postharvest Technology, Department of Food Science, Stellenbosch University, Stellenbosch 7602, South Africa

${ }^{g}$ VCBT, Flanders Centre of Postharvest Technology, Willem de Croylaan 42, 3001 Heverlee, Belgium

\footnotetext{
* Corresponding author. Tel.: tel. +41 (0)58 7654790.

E-mail address: defraeye@arch.ethz.ch
} 
Defraeye T., Cronjé P., Verboven P., Opara U.L., Nicolai B. (2015), Exploring ambient loading of citrus fruit into reefer containers for cooling during marine transport using computational fluid dynamics, Postharvest Biology and Technology 108, 91-101.

http://dx.doi.org/10.1016/j.postharvbio.2015.06.004

\section{Abstract}

A promising cold-chain protocol is explored as an alternative to the commonly-used forced-air pre-cooling (FAC) of citrus fruit prior to shipping: ambient loading of fruit in reefer containers for cooling during long-haul marine transport. Despite the multiple logistical and economical savings it provides, the potential of "ambient loading" of fruit in reefer containers has been left largely unexplored. The present study targets this aspect, but also cooling by vertical airflow in general. Computational fluid dynamics (CFD) is used to identify differences in cooling rate and uniformity between individual boxes at different heights on a pallet and between individual fruit within a single box. Simulations show that low airflow rates, typical for refrigerated containers, do not only induce slower fruit cooling, compared to FAC airflow rates, but also the cooling heterogeneity between different layers of boxes (in height) and between individual fruit in a single box is larger. In addition, the presence of gaps between pallets invokes airflow short-circuiting, leading to highly reduced fruit cooling rates. Finally, strategies for future improvement of the ambient loading protocol are proposed, which in the first place should target faster and more uniform cooling.

\section{$\underline{\text { Keywords }}$}

computational fluid dynamics; package design; cold chain; airflow short-circuits; vent holes; convective transfer 
Defraeye T., Cronjé P., Verboven P., Opara U.L., Nicolai B. (2015), Exploring ambient loading of citrus fruit into reefer containers for cooling during marine transport using computational fluid dynamics, Postharvest Biology and Technology 108, 91-101.

http://dx.doi.org/10.1016/j.postharvbio.2015.06.004

\section{Introduction}

Ambient (warm) loading of citrus fruit into refrigerated containers (reefer) for cooling during marine transport can serve as an alternative for well-established forced-air pre-cooling (FAC) of produce, either inland or at the harbour, prior to shipping overseas (Defraeye et al., 2015; Heap, 2006; Thompson, 2004). It is also frequently used for banana fruit (Jedermann et al., 2014, 2013). Ambient loading differs strongly from FAC (Figure 1) as it implies vertical airflow, much lower airflow rates and a lower installed cooling capacity, which are prescribed by the refrigerated container type. This cold-chain strategy is of interest if FAC facilities are not available (e.g., in some developing countries) or if the volumes of fruit to be exported exceed the capacity of available pre-cooling facilities. Ambient loading also reduces the time and cost to handle and pre-cool the pallets at these facilities. Furthermore, when applied immediately after palletisation at the packinghouse, the cold chain starts earlier compared to when pre-cooling occurs at the harbour, since transport to these facilities is often unrefrigerated. As such, ambient loading does not only provide significant logistical and economical savings, but can also aid in mitigating postharvest losses. These losses can be as high as $40 \%$ in fruit and vegetable supply chains (Gustavsson et al., 2011), particularly in developing countries, and are mainly caused by the lack of an appropriate cold chain (IIR, 2009).

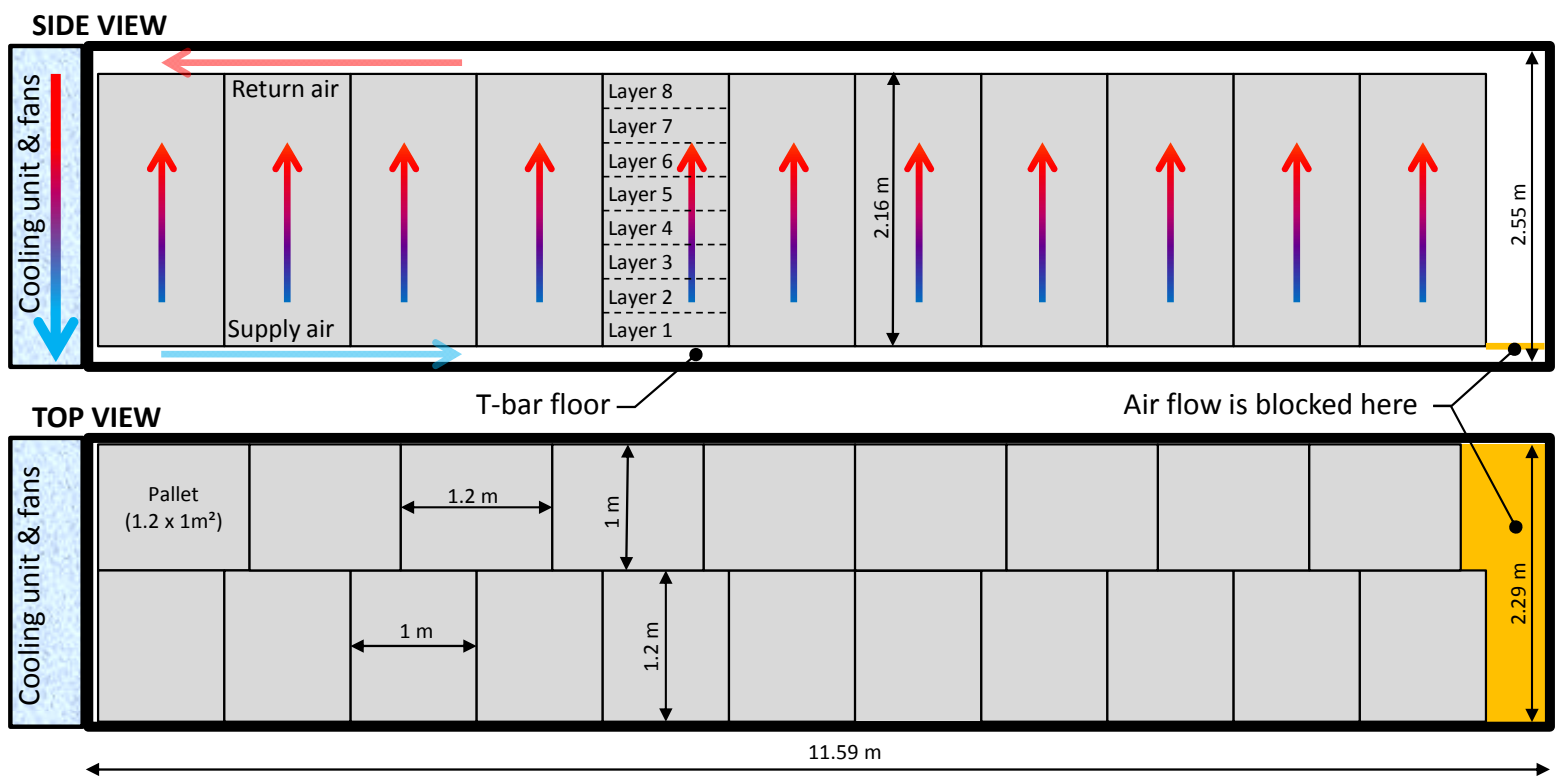


Defraeye T., Cronjé P., Verboven P., Opara U.L., Nicolai B. (2015), Exploring ambient loading of citrus fruit into reefer containers for cooling during marine transport using computational fluid dynamics, Postharvest Biology and Technology 108, 91-101.

http://dx.doi.org/10.1016/j.postharvbio.2015.06.004

Figure 1. Side and top cross-sectional views of a refrigerated container (12.2 m, 40 feet), equipped with a refrigeration unit, with a typical stacking pattern of the $\mathbf{2 0}$ pallets and indication of the box layers stacked on a pallet. The inner dimensions of the container are given (figure adapted from (Defraeye et al., 2015)).

The success and potential impact of this promising cooling protocol, however, depends on how fast the produce field heat can be removed by cooling with vertical airflow in the reefer container, as postharvest quality and shelf life are strongly governed by the produce temperature history (Robertson, 2013; Thompson et al., 2008). Recent studies on citrus and banana fruit identified that the limiting factor for the cooling rate of the fruit is the amount of energy that can be transferred from the fruit to its surrounding environment, and not the installed cooling capacity of the reefer container, even though the latter is much lower than for normal FAC facilities (Defraeye et al., 2015; Jedermann et al., 2014). As such, the available cooling capacity of a reefer container is not utilised to its full extent. The consequence of this lower fruit cooling rate is that ambient loading (in the South African citrus industry) is currently only successful for 'Valencia' type citrus cultivars, and is less effective for mandarins or 'Navel' oranges as they are more prone to postharvest decay and physiological disorders. As this technique evolved from industrial trial-and-error, its optimisation potential with respect to cooling rate, fruit quality, shelf life and associated food losses is however highly uncharted. This practice is also virtually unexplored for other, more perishable fruit species. Hence, a more systematic evaluation of the ambient loading protocol is paramount for further industrial implementation and optimisation.

In general, little research has been performed on the cooling process of fruits or vegetables inside refrigerated containers during transport. This is rather surprising as huge amounts of perishable foods are transported overseas, where refrigerated containers have almost fully replaced bulk reefer vessels in the past decade (Arduino et al., 2013; Fitzgerald et al., 2011). Most container cooling studies relied on basic calculations or experiments (Defraeye et al., 2015; Hoang et al., 2012; Jedermann et al., 2013; Jiménez-Ariza et al., 2014; Rodríguez-Bermejo et al., 2007; Smale et al., 2006; Tanner and Amos, 2003) and, to the best of our knowledge, only very few dealt with ambient loading (Defraeye et al., 2015; Jedermann et al., 2014, 2013). In particular, fullscale container experiments are expensive and time-consuming and only allow for a rather limited number of 
Defraeye T., Cronjé P., Verboven P., Opara U.L., Nicolai B. (2015), Exploring ambient loading of citrus fruit into reefer containers for cooling during marine transport using computational fluid dynamics, Postharvest Biology and Technology 108, 91-101.

http://dx.doi.org/10.1016/j.postharvbio.2015.06.004

measuring points ( $10-100$ sensors), compared to the amount of fruit in the container ( 10 individual fruit), which inhibits an in-depth parametric evaluation of the factors influencing the cooling process. In addition, such experiments inherently have limitations regarding repeatability, sensitivity to small changes and experimental uncertainty.

The aforementioned techniques are thus less suitable to address specific knowledge gaps for the virtuallyunexplored ambient loading protocol, such as: (1) an identification of the cooling rate (e.g., seven-eighths cooling time) and its uniformity between individual fruit in a box but also between individual boxes at different heights on a pallet (layers in Figure 1); (2) the impact of airflow short-circuits, i.e., gaps in between individual pallets, via which refrigerated air can bypass the produce since they can significantly reduce fruit cooling rates. Although such short-circuits can be easily avoided under FAC by closing them prior to cooling (Fraser and Eng, 1998; Thompson, 2004), this is less straightforward for container cooling due to the limited accessibility, which makes such short-circuits critical determinants of the cooling process here. To address these questions regarding produce cooling behaviour in refrigerated containers, computational fluid dynamics (CFD) is a more appropriate tool and nicely complements basic calculations and experiments. CFD has been applied extensively within a FAC context (Defraeye et al., 2014, 2013a; Dehghannya et al., 2012, 2011, 2010; Delele et al., 2013a, 2013b; Ferrua and Singh, 2011, 2009a, 2009b; Smale et al., 2006; Verboven et al., 2006; Zou et al., 2006a, 2006b), but only to a very limited extent for cooling during transport (James et al., 2006; Moureh and Flick, 2004; Moureh et al., 2009, 2002; Tapsoba et al., 2007, 2006), predominantly for refrigerated vehicles.

In the present study, CFD is used to gain a deeper insight on the ambient loading protocol for cooling citrus fruit during marine transport in refrigerated containers. To this end, differences in cooling behaviour between individual boxes on a pallet and between individual fruit in a single box are identified by assessing cooling rates and uniformity. To explore cooling by vertical airflow in a more general way, higher airflow rates (characteristic of FAC) than those common for container cooling were evaluated as well. Comparison is made with previous FAC results for horizontal pre-cooling for the same box design (Defraeye et al., 2014). Furthermore, the influence of airflow short-circuits between pallets on the cooling behaviour is investigated by evaluating different gap widths 
Defraeye T., Cronjé P., Verboven P., Opara U.L., Nicolai B. (2015), Exploring ambient loading of citrus fruit into reefer containers for cooling during marine transport using computational fluid dynamics, Postharvest Biology and Technology 108, 91-101.

http://dx.doi.org/10.1016/j.postharvbio.2015.06.004

between pallets. In addition to a better insight in the cooling behaviour of citrus fruit for vertical cooling, this study provides an outlook towards further improvements of the ambient loading protocol, which in the first place targets faster and more uniform cooling.

\section{Materials and methods}

\subsection{Packaging, palletisation and containerization}

A telescopic corrugated fibreboard box type 'Supervent' was used ( $0.4 \times 0.3 \times 0.27 \mathrm{~m}$, Figure 2a), filled with 'Navel' oranges (Citrus senensis L. Osb). The carton box has half-circular vent holes, located at the top and bottom of each side. This box was already evaluated for FAC by Defraeye et al. (Defraeye et al., 2014, 2013a). On a pallet, 8 layers of boxes are stacked, where each layer holds 10 boxes (Figure 2b). The 'Supervent' package was designed to form horizontal ventilation pathways via the vent holes for pre-cooling after palletisation. Though this box design also enables vertical pathways in principle, these are less evident in practice due to the staggered stacking pattern of consecutive layers (Figure $2 \mathrm{~b}$ ). This is required to ensure stability of the pallet during handling and transport but results in the obstruction of several vent holes. In addition, the slats of the wooden pallet base fully or partially cover some of the vent holes of the bottom carton box. 
Defraeye T., Cronjé P., Verboven P., Opara U.L., Nicolai B. (2015), Exploring ambient loading of citrus fruit into reefer containers for cooling during marine transport using computational fluid dynamics, Postharvest Biology and Technology 108, 91-101.

http://dx.doi.org/10.1016/j.postharvbio.2015.06.004
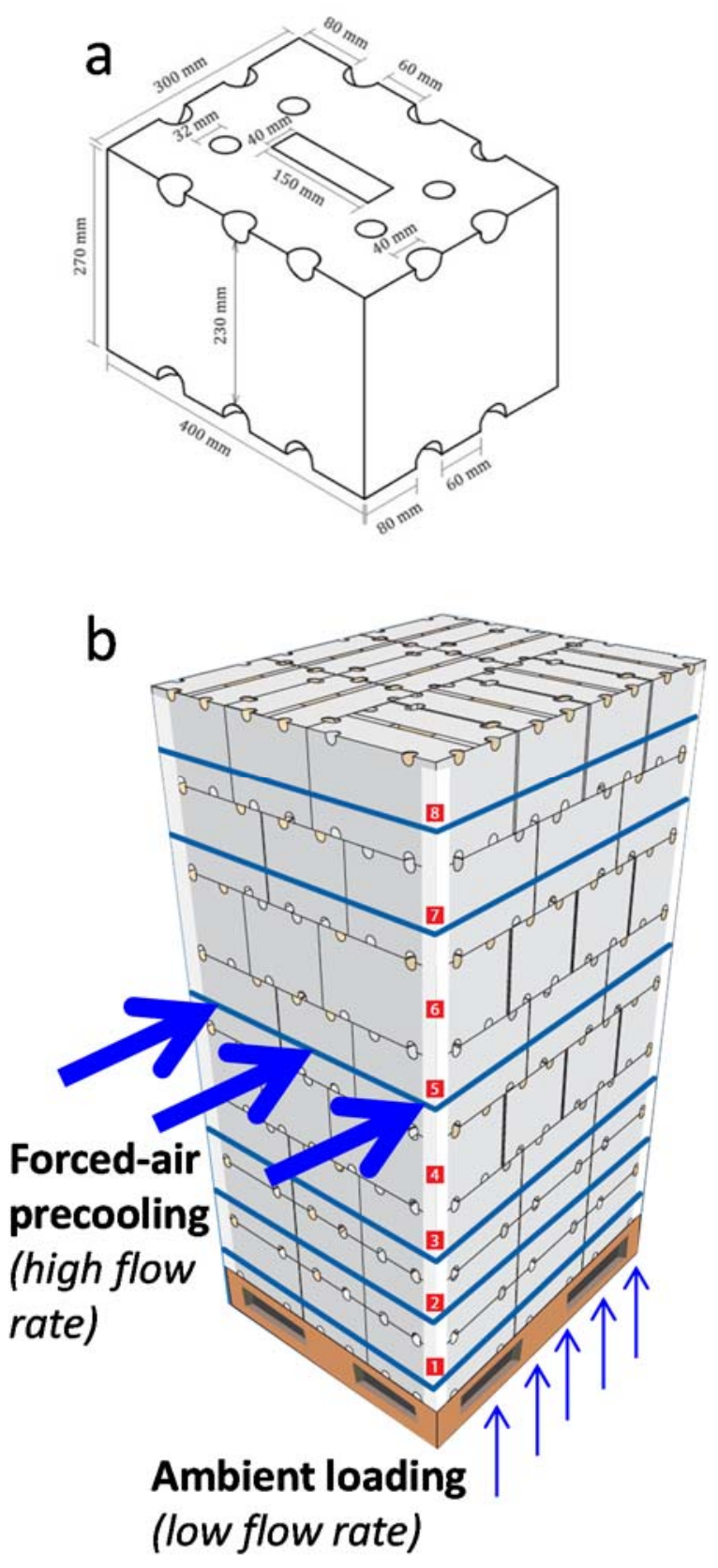

Figure 2. (a) Geometry and dimensions of the Supervent box used in the present study but also by (Defraeye et al., 2014, 2013a); (b) Illustration of airflow for forced-air pre-cooling (horizontal flow) and ambient loading in a refrigerated container (vertical airflow) for an 8-layer, high-cube citrus pallet (10 Supervent cartons per layer, each packed with about $16 \mathrm{~kg}$ of fruit). Note that a slightly different design of the Supervent box is shown here, with fewer ventilation holes. 
Defraeye T., Cronjé P., Verboven P., Opara U.L., Nicolai B. (2015), Exploring ambient loading of citrus fruit into reefer containers for cooling during marine transport using computational fluid dynamics, Postharvest Biology and Technology 108, 91-101.

http://dx.doi.org/10.1016/j.postharvbio.2015.06.004

\subsection{Numerical model}

A computational model was constructed to study citrus cooling by vertical airflow through Supervent boxes, as stacked on pallets in a refrigerated container. This (base) model is shown in Figure 3a with its dimensions and boundary conditions. Two approaches can be applied to represent the fruit in the boxes. In the porous medium approach (Ambaw et al., 2014, 2013b; Nahor et al., 2005; Verboven et al., 2006), the fruit are modelled in bulk in the boxes as a porous medium. This approach allows modelling large ensembles of boxes, for example an entire cool room or a refrigerated container, but it does not provide information on cooling heterogeneity among individual fruit within a single box. In a second approach, the individual fruit can be modelled discretely (Defraeye et al., 2014; Delele et al., 2008). Although it is only possible to model much smaller ensembles of fruit and boxes, the cooling behaviour of each individual fruit can be monitored. In addition, such discrete models can be used to derive the model coefficients that are required for the porous medium approach. For these reasons, this second approach was applied in this study, as depicted in Figure 3.

Some simplifications were made to keep the model complexity and computational cost within limits. First, only one (vertical) row of boxes was modelled instead of an entire pallet or an ensemble of pallets in a container. To this end, symmetry was assumed on all sides of the row. Such a configuration mimics an idealised box stacking, where the vertical ventilation pathways for airflow are maximised, and does not address differential cooling among pallets at different positions within the container (Figure 1). In addition, no vertical (or horizontal) gaps between the boxes are accounted for in the base model. Furthermore, the blockage of a part of the vent holes of the lower box by the wooden pallet base is not included. These simplifications render the computational model to a rather idealised case, which will exhibit a somewhat faster cooling rate than in practice (Figure $2 b$ ).

Individual oranges were modelled discretely as spheres with a diameter of $80 \mathrm{~mm}$. Each box held 64 oranges (i.e., $16.5 \mathrm{~kg}$ ) and was filled according to a staggered pattern. The total amount of oranges in the computational model ( 8 boxes) equalled 512 . The upstream and downstream sections of the computational domain were taken 
Defraeye T., Cronjé P., Verboven P., Opara U.L., Nicolai B. (2015), Exploring ambient loading of citrus fruit into reefer containers for cooling during marine transport using computational fluid dynamics, Postharvest Biology and Technology 108, 91-101.

http://dx.doi.org/10.1016/j.postharvbio.2015.06.004

sufficiently long to avoid an influence of inlet and outlet boundary conditions on the flow in the proximity of the boxes.

(a) Base model

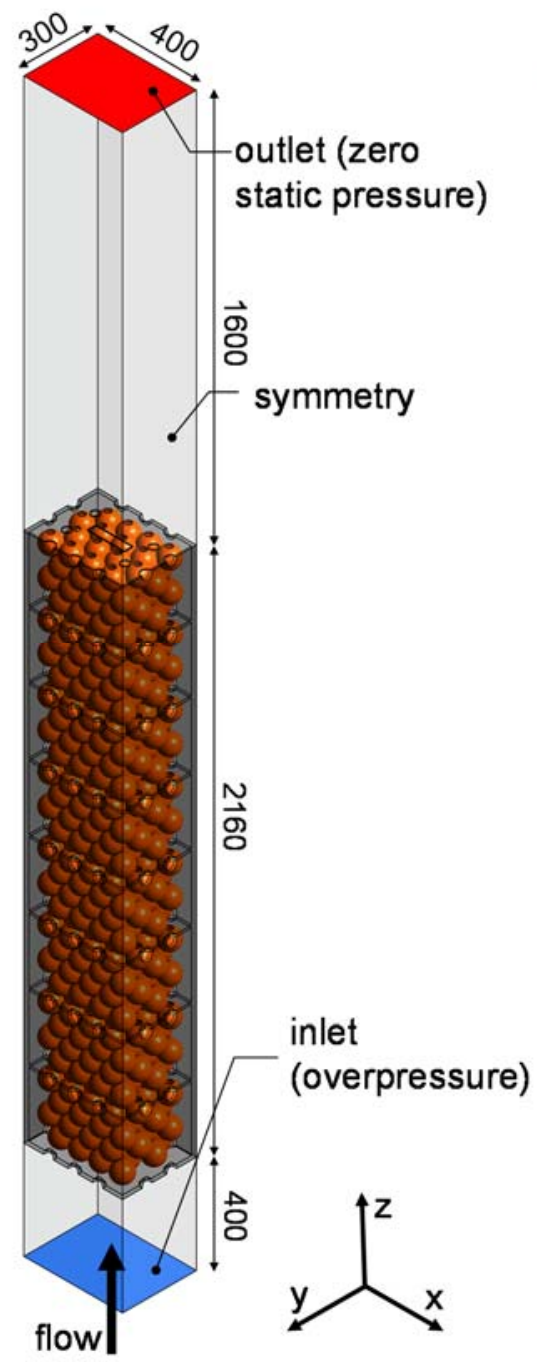

(b) Gap model

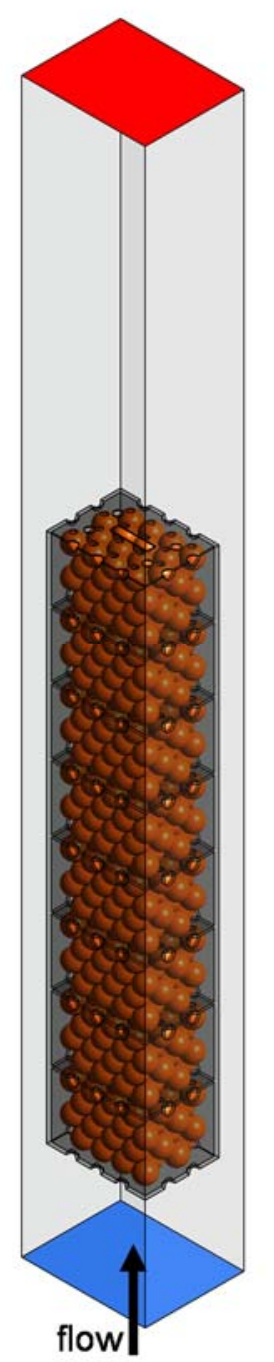

Figure 3. Computational model and boundary conditions for two cases: base model and gap model for one row of boxes, composed out of 8 layers. Dimensions are in millimetres.

Apart from the aforementioned base model, another computational model was constructed (Figure $3 \mathrm{~b}$ ) to quantify the impact of vertical gaps (short-circuits) between individual pallets in a container. Gaps between pallets should be avoided as much as possible as they negatively affect the cooling rate (GDV, 2014). Such airflow bypasses will however always be present to some extent, as detailed in section 3.4. When no measures are taken, 
Defraeye T., Cronjé P., Verboven P., Opara U.L., Nicolai B. (2015), Exploring ambient loading of citrus fruit into reefer containers for cooling during marine transport using computational fluid dynamics, Postharvest Biology and Technology 108, 91-101.

http://dx.doi.org/10.1016/j.postharvbio.2015.06.004

even $9 \%$ of the container's surface area remains uncovered for a $12.2 \mathrm{~m}$ (40 feet) container, when it is entirely filled with standard pallets.

This was done in a simplified way by including a vertical gap all around the row of boxes of the base model. The following gap widths (horizontally between adjacent rows of boxes, $x$ and $y$ direction) were evaluated: $6.25 \mathrm{~mm}$, $25 \mathrm{~mm}$ and $100 \mathrm{~mm}$. As symmetry conditions were applied for the lateral sides, only half of the gap width was included in the computational model (Figure 3b). These gap widths correspond to a gap area (only considering half the gap width), relative to the total box base plane $(0.4 \times 0.3 \mathrm{~m})$ of $3.7 \%, 15 \%$ and $67 \%$. As such, these computational models have an increased surface area at the inlet and outlet. These gap widths correspond to equivalent gaps between single pallets (base area for pallet holding 10 boxes $=1.2 \times 1 \mathrm{~m}^{2}$ ) of $10 \mathrm{~mm}, 40 \mathrm{~mm}$ and $159 \mathrm{~mm}$ respectively. In total, four computational models were made: the base model and gap models for 3 gap widths.

The computational grids are hybrid grids (hexahedral and tetrahedral cells) with $4.1 \times 10^{6}$ cells for the base model and $4.9 \times 10^{6}, 5.9 \times 10^{6}$ and $7.2 \times 10^{6}$ cells for models with gaps of $6.25 \mathrm{~mm}, 25 \mathrm{~mm}$ and $100 \mathrm{~mm}$, respectively. The spatial discretisation error was estimated by means of Richardson extrapolation (Franke et al., 2007; Roache, 1994) and was about $2.5 \%$ for the mass flow rate through the boxes and $5 \%$ for the heat flow from the oranges.

At the inlet of the domain, an overpressure was imposed, i.e., as delivered by the evaporator fans in the refrigeration unit of the container. At the outlet, the ambient atmospheric pressure was imposed. Six pressure differentials between inlet and outlet were evaluated for the base model (no gaps) to investigate the effect of airflow rate on cooling rate: $1 \mathrm{~Pa}, 3.16 \mathrm{~Pa}\left(=10^{1 / 2}\right), 10 \mathrm{~Pa}, 100 \mathrm{~Pa}, 1000 \mathrm{~Pa}$ and $10000 \mathrm{~Pa}$. These pressure differentials were chosen in order to obtain airflow rates in the simulations that are realistic for refrigerated container cooling but also for industrial forced-air pre-cooling (FAC), since the latter allows comparison with previous results for horizontal FAC (Defraeye et al., 2014, 2013a). This wide range of air speeds allows the exploration of the cooling behaviour of spherical horticultural produce by vertical airflow in a more general 
Defraeye T., Cronjé P., Verboven P., Opara U.L., Nicolai B. (2015), Exploring ambient loading of citrus fruit into reefer containers for cooling during marine transport using computational fluid dynamics, Postharvest Biology and Technology 108, 91-101.

http://dx.doi.org/10.1016/j.postharvbio.2015.06.004

context. The corresponding specific flow rates $\left(\mathrm{L} \mathrm{s}^{-1} \mathrm{~kg}^{-1}\right)$, i.e. per mass of fruit, and average air speeds at the inlet of the computational domains are given in Table 1 . The resulting range of airflow rate is realistic since typical flow rates are: for FAC $\approx 1$ to $3 \mathrm{~L} \mathrm{~s}^{-1} \mathrm{~kg}^{-1}$ (Brosnan and Sun, 2001; Defraeye et al., 2013a; Thompson et al., 2008); for refrigerated containers $\approx 0.02-0.06 \mathrm{~L} \mathrm{~s}^{-1} \mathrm{~kg}^{-1}$ (for a Maersk Starcool refrigeration unit installed on a $12.2 \mathrm{~m}$ (40 feet) container, obtained from personal communication with Maersk). The gap models were evaluated using the same value of the average air speed at the inlet as in the base model (Table 1), but only for three different speeds. This boundary condition implies the same flow rate at the inlet per meter square. Imposing the same speeds allows a more straightforward comparison of the cooling rates, compared to imposing the same pressure differences. The reason is that the flow resistance of the gap models is much lower, which would induce higher air speeds through the inlet at a certain imposed pressure. The higher flow rates for the gap models (Table 1) are a direct result of the increased surface area of the inlet.

Table 1. Pressure difference between inlet and outlet and flow rate for all computational models at different average air speeds at the inlet of the computational domain.

\begin{tabular}{|c|c|c|c|c|c|c|c|c|c|c|c|c|}
\hline $\begin{array}{l}\text { Average speed at } \\
\text { inlet }\left(\mathrm{m} \mathrm{s}^{-1}\right)\end{array}$ & 0.0235 & 0.0443 & 0.0812 & 0.265 & 0.844 & 2.68 & 0.0235 & 0.0443 & 0.0812 & 0.265 & 0.844 & 2.68 \\
\hline & \multicolumn{6}{|c|}{ Pressure (Pa) } & \multicolumn{6}{|c|}{ Flow rate per fruit mass $\left(\mathrm{L} \mathrm{s}^{-1} \mathrm{~kg}^{-1}\right)$} \\
\hline Base model & 1 & 3.16 & 10 & 100 & 1000 & 10000 & 0.0214 & 0.0403 & 0.0740 & 0.241 & 0.769 & 2.44 \\
\hline $\begin{array}{l}\text { Gap model } 6.25 \\
\mathrm{~mm}\end{array}$ & 0.853 & - & - & 50.6 & - & 3816 & 0.0222 & - & - & 0.250 & - & 2.53 \\
\hline $\begin{array}{l}\text { Gap model } 25 \\
\mathrm{~mm}\end{array}$ & 0.114 & - & - & 5.52 & - & 411 & 0.0247 & - & - & 0.278 & - & 2.81 \\
\hline $\begin{array}{l}\text { Gap model } 100 \\
\mathrm{~mm}\end{array}$ & 0.00436 & - & - & 0.295 & - & 24.4 & 0.0357 & - & - & 0.402 & - & 4.07 \\
\hline
\end{tabular}

A low turbulence intensity (0.05\%) was imposed for flow entering the computational domain at the inlet, similar to Defraeye et al. (Defraeye et al., 2013a). A constant air temperature was imposed at the inlet, which implicitly assumes that the refrigeration unit is able to cool the return air entirely back to the set temperature, which might 
Defraeye T., Cronjé P., Verboven P., Opara U.L., Nicolai B. (2015), Exploring ambient loading of citrus fruit into reefer containers for cooling during marine transport using computational fluid dynamics, Postharvest Biology and Technology 108, 91-101.

http://dx.doi.org/10.1016/j.postharvbio.2015.06.004

not always be the case in practice. The inlet air temperature was taken lower than for normal pre-cooling $(\approx 2-4$

${ }^{\circ} \mathrm{C}$, e.g., (Thompson, 2003)), namely $-0.5^{\circ} \mathrm{C}$. The reason for this low temperature is that this research was conducted for the South African citrus industry, which exported 1.5 million tonnes during the 2013 season, making it the third largest exporter of fresh citrus worldwide (CGA, 2013). Several of its export markets demand a cold disinfestation treatment as a risk mitigation protocol for pests that may be associated with the fruit export pathway. Citrus fruit exported from South Africa to USA, Korea, Thailand and China undergoes a cold disinfestation treatment of $22-24 \mathrm{~d}$ at $-0.6^{\circ} \mathrm{C}$ ( $12 \mathrm{~d}$ for Japan). This phytosanitary treatment is used to disinfest fruit of insect larvae of major citrus pests in South Africa such as false codling moth (Thaumatotibia leucotreta (Carpenter et al., 2007)) and Mediterranean fruit fly (Ceratitis capitata (White and Elson, 2004)). To comply with this cold disinfestation protocol, citrus fruit are pre-cooled to sub-zero temperatures $\left(\approx-0.6^{\circ} \mathrm{C}\right)$ prior to officially starting the cold disinfestation protocol. This protocol entails a lower throughput in the pre-cooling facilities and this temperature has to be maintained for several weeks during overseas transport. Ambient loading is particularly of interest for the South African citrus industry since more of its current export markets as well as new markets in the Far East ask for a cold disinfestation treatment. This increasing demand will outpace the current capacity of pre-cooling facilities and associated infrastructure investments.

The lateral boundaries were modelled as a symmetry boundary condition (slip wall), which assumes that the normal velocity component and the normal gradients at the boundary are zero. The cardboard boxes and the fruit surfaces were modelled as no-slip walls with zero roughness. The main asperities for oranges are the lenticels, which are typically below $1 \mathrm{~mm}$. Such asperities are of the same order of magnitude or smaller than the laminar sublayer thickness at the flow speeds evaluated in this study (Defraeye et al., 2012). The initial temperature of the fruit and cardboard was taken equal to the characteristic fruit temperature after being packed and palletised, which was typically $20^{\circ} \mathrm{C}$ for South Africa. 
Defraeye T., Cronjé P., Verboven P., Opara U.L., Nicolai B. (2015), Exploring ambient loading of citrus fruit into reefer containers for cooling during marine transport using computational fluid dynamics, Postharvest Biology and Technology 108, 91-101.

http://dx.doi.org/10.1016/j.postharvbio.2015.06.004

\subsection{Numerical simulation}

In the past, CFD has been extensively applied to model fluid flow for several food processing applications (Ambaw et al., 2013a; Norton and Sun, 2006; Norton et al., 2013; Smale et al., 2006; Verboven et al., 2006; Xia and Sun, 2002). The accuracy of CFD simulations depends to a large extent on the turbulence-modelling and boundarylayer modelling approaches that are used. In this study, Reynolds-averaged Navier-Stokes (RANS) was applied in combination with the shear stress transport $k-\omega$ model (SST k- $\omega$; (Menter, 1994)). It was not feasible to mesh the boundary-layer region fine enough to apply low-Reynolds number modelling to resolve the transport in the boundary layer on the no-slip surfaces (e.g., fruit) since the computational cost would be too large and such grid generation is very challenging for the configuration under study. Therefore, the wall-function approach was used. Despite being less accurate (e.g., (Defraeye et al., 2013b, 2010)), wall functions are often the only option as lowReynolds number modelling is not practically applicable for complex 3-D configurations (Defraeye et al., 2012; Kondjoyan, 2006). The RANS SST $\mathrm{k}$ - $\omega$ turbulence model in combination with wall functions was applied in a related study on cooling of orange fruit (Defraeye et al., 2013a) with a very similar configuration. The satisfactory agreement with experimental data indicated a sufficient accuracy of the CFD simulations. Other studies using this turbulence model with wall functions also found a good agreement with experiments (Ambaw et al., 2013c; Delele et al., 2009).

The simulations were performed with the CFD code ANSYS Fluent 13 (ANSYS, Canonsburg, PA). Second-order discretisation schemes were used throughout. The SIMPLE algorithm was used for pressure-velocity coupling. Pressure interpolation was second order. Buoyancy effects were considered negligible and were not taken into account in the simulations. The assumption essentially means that no temperature-driven density difference flow is modelled, so only forced-convective flow is considered. In addition, this implies that the temperature does not influence the flow field by which heat is considered to be a passive scalar. Radiation was neglected due to the relatively low temperature differences between the surfaces. It is usually considered small compared to convective heat transfer in industrial cooling applications (Kondjoyan, 2006). Heat of respiration was not included in the model since it is quite low for oranges $\left(\sim 0.050 \mathrm{~W} \mathrm{~kg}^{-1}\right.$, (ASHRAE, 2010)) and therefore is unlikely to have a 
Defraeye T., Cronjé P., Verboven P., Opara U.L., Nicolai B. (2015), Exploring ambient loading of citrus fruit into reefer containers for cooling during marine transport using computational fluid dynamics, Postharvest Biology and Technology 108, 91-101.

http://dx.doi.org/10.1016/j.postharvbio.2015.06.004

significant impact on the cooling rate of fresh horticultural produce, as reported already for forced-air pre-cooling (Brosnan and Sun, 2001; Gowda et al., 1997). Mass loss of the fruit and the resulting latent heat of evaporation were also not included in the model since the mass loss was very small (below $1 \%$ from experimental measurements, results not reported). Iterative convergence of the numerical simulation was assessed by monitoring the velocity, turbulent kinetic energy and temperature at specific locations in the flow field, and the heat fluxes (surface-averaged values) on the fruit surfaces. The thermal properties of the oranges that were used in the simulations were: a density of $960 \mathrm{~kg} \mathrm{~m}^{-3}$, a thermal conductivity of $0.386 \mathrm{~W} \mathrm{~m}^{-1} \mathrm{~K}^{-1}$ and a specific heat capacity of $3850 \mathrm{~J} \mathrm{~kg}^{-1} \mathrm{~K}^{-1}$ (see (Defraeye et al., 2014)). These properties were taken constant, thus independent of temperature. Note that heat transfer in the cardboard boxes was also solved for (density $=145 \mathrm{~kg} \mathrm{~m}^{-3}$, thermal conductivity $=0.064 \mathrm{~W} \mathrm{~m}^{-1} \mathrm{~K}^{-1}$, specific heat capacity $\left.=1338 \mathrm{~J} \mathrm{~kg}^{-1} \mathrm{~K}^{-1}\right)$. The impact of these boxes will, however, be rather limited due to their low thermal capacity and their insulating effect.

Before simulating the transient cooling process, steady-state simulations were performed to obtain the flow field and the initial temperature conditions. During these simulations, the temperature of the boxes and fruit were fixed to their initial value $\left(20^{\circ} \mathrm{C}\right)$ and the inlet temperature was taken equal to the container air temperature set point $\left(-0.5^{\circ} \mathrm{C}\right)$. After the steady-state simulations, transient simulations of the pre-cooling process were performed. Since the flow field was assumed steady and stable over time as no buoyancy was included in the model amongst others, the flow field did not need to be recomputed anymore during the transient simulations and thus the flow equations were switched off. As such, the computational cost was significantly reduced since only the energy equation needed to be solved over time. Due to the large differences in cooling rates for different cases (see section 3), each simulation was run for a different time period. All simulations were run with a time step of $60 \mathrm{~s}$, which was determined from a temporal sensitivity analysis. The simulations (for a time period of $20 \mathrm{~h}$ after the start of cooling) took roughly $2 \mathrm{~d}$ on a 12 core Intel Xeon processor $(2.66 \mathrm{GHz})$ with 48GB RAM memory. 
Defraeye T., Cronjé P., Verboven P., Opara U.L., Nicolai B. (2015), Exploring ambient loading of citrus fruit into reefer containers for cooling during marine transport using computational fluid dynamics, Postharvest Biology and Technology 108, 91-101.

http://dx.doi.org/10.1016/j.postharvbio.2015.06.004

\subsection{Evaluation of cooling rate}

The cooling rate of each box was assessed by monitoring the internal temperature of the oranges. In field or laboratory experiments, usually the fruit pulp temperature is measured with a sensor (e.g., thermocouple), located in the centre of an orange. This pulp temperature is critical in a cold disinfestation protocol as only this temperature, measured at various positions in a refrigerated container, is used to verify compliance with the protocol. With CFD however, temperature information is available in each control volume of the computational mesh by which the average fruit temperature can also be determined, i.e., of a single fruit or of all fruit within a box. Such a volume-averaged quantity is considered more representative as the core of an orange is generally the last location of the entire fruit to reach the required set temperature, whereas the rest of the fruit will already be slightly below this temperature. Two temperatures were monitored in the simulations: the core temperature of a single orange $\left(T_{c}\right)$, located in the central part of each box on the pallet (thus 8 virtual sensors in total), and the average temperature of all fruit within each box $\left(T_{a v g, b o x}\right)$.

From these temperature profiles $\left(T=T_{c}\right.$ or $\left.T_{\text {avg,box }}\right)$, the fractional unaccomplished temperature change $(Y)$ could be determined:

$Y=\frac{T-T_{a}}{T_{i}-T_{a}}$

where subscripts $i$ and $a$ represent the initial temperature of the fruit $\left(20^{\circ} \mathrm{C}\right)$ and the set cooling air temperature of the container $\left(-0.5^{\circ} \mathrm{C}\right)$, respectively. From this $Y$ value, the seven-eighths cooling time $\left(\mathrm{SECT}, t_{7 / 8}\right)$ was determined, which is the time required to reduce the temperature difference between the fruit and the cooling air by seven eighths $(Y=0.125)$. The SECT temperature $\left(T_{7 / 8}\right)$ equals $2.06^{\circ} \mathrm{C}$. The SECT is particularly interesting in commercial cooling operations because the fruit temperature is then acceptably close to the required storage temperature and the remaining heat load can be removed with less energy costs (Brosnan and Sun, 2001). The SECT based on $T_{a v g, b o x}$ can be considered more representative as it provides a general appreciation of the amount of heat to be cooled away from all fruit within the box, though it cannot be obtained experimentally in a 
Defraeye T., Cronjé P., Verboven P., Opara U.L., Nicolai B. (2015), Exploring ambient loading of citrus fruit into reefer containers for cooling during marine transport using computational fluid dynamics, Postharvest Biology and Technology 108, 91-101. http://dx.doi.org/10.1016/j.postharvbio.2015.06.004

straightforward way. The SECT is actually a characteristic of the system which also depends on fruit stacking pattern in the boxes, the design of the packaging (i.e., location of vent holes and total vent area) but also the stacking of individual boxes on a pallet.

When an exponentially decaying cooling curve is assumed and the heat transport properties and airflow are taken independent of temperature (Thompson et al., 2008), the cooling behaviour should be quasi-independent of the set air temperature. As such, the SECT should be the same for different set air temperatures as it is a characteristic of the cooling process. Hence, in principle, the obtained SECT results for a set temperature of -0.5 ${ }^{\circ} \mathrm{C}$ are valid for lower or higher set air temperatures as well (see (Defraeye et al., 2014). The value of the set air temperature will thus not affect the conclusions with respect to the SECT and the differences between the considered cases. This remark is relevant for ambient loading using the cold disinfestation treatment. In this case, the set air temperature of the container (now at $-0.5^{\circ} \mathrm{C}$ ) will probably be taken a bit lower in practice (e.g., -1.5 $\left.{ }^{\circ} \mathrm{C}\right)$ to reach the required orange pulp temperature $\left(\approx-0.5^{\circ} \mathrm{C}\right)$ faster.

Apart from the SECT, the convective heat transfer coefficient $(\mathrm{CHTC})$ will also be determined, more particularly to assess the cooling heterogeneity between individual oranges in a box (in section 3.2). The CHTC is defined as: $\mathrm{CHTC}=q_{c, w} /\left(T_{w}-T_{a}\right)$. The $\mathrm{CHTC}$ relates the convective heat flux normal to the surface $\left(q_{c, w}\left[\mathrm{~J} \mathrm{~s}^{-1} \mathrm{~m}^{-2}\right]\right)$, i.e., at the airmaterial interface, to the difference between the fruit surface temperature $\left(T_{w}\left[{ }^{\circ} \mathrm{C}\right.\right.$ or $\left.\left.\mathrm{K}\right]\right)$ and a reference temperature $\left(T_{\text {ref }}\left[{ }^{\circ} \mathrm{C}\right.\right.$ or $\left.\left.\mathrm{K}\right]\right)$. For this reference temperature, the set cooling air temperature $\left(T_{a}\right)$ was taken in this study. As the CHTCs were determined at the start of the simulations, $T_{w}$ is the initial fruit temperature $\left(20^{\circ} \mathrm{C}\right)$. As this temperature difference $\left(T_{w}-T_{a}\right)$ was constant over all fruit surfaces when calculating the CHTC, the CHTC is actually directly proportional to the heat flux at the wall here $\left(q_{c, w}\right)$. Note that the $\mathrm{CHTC}$ is actually a defined quantity, based on known information on the heat transfer at the fruit surfaces. Its value strongly depends on the choice of the reference temperature, for which also other values (than $T_{a}$ ) can be taken, such as the air temperature at the vent hole inlets of each box. As we will only evaluate the distribution of the CHTC over the individual fruit in a box (in section 3.2), and not the absolute values of the CHTCs, the choice of the reference temperature is less critical. 
Defraeye T., Cronjé P., Verboven P., Opara U.L., Nicolai B. (2015), Exploring ambient loading of citrus fruit into reefer containers for cooling during marine transport using computational fluid dynamics, Postharvest Biology and Technology 108, 91-101.

http://dx.doi.org/10.1016/j.postharvbio.2015.06.004

\section{$\underline{\text { 3. Results }}$}

\subsection{Influence of fruit temperature}

The impact of the fruit temperature used to determine the SECT, namely $T=T_{c}$ or $T_{a v g, b o x}$, is evaluated in Figure 4 for the base model (without gap). For both average and core fruit temperatures, the SECT is given for all layers of boxes as a function of the average air speed at the inlet of the computational domain. As expected, the average temperature of the fruit in a single box $\left(T_{a v g, b o x}\right)$ reaches the SECT temperature $\left(T_{7 / 8}\right)$ before the core temperature $\left(T_{c}\right)$ does, resulting in lower SECT. However, the differences are relatively limited for all boxes. The factor $t_{7 / 8}\left(T_{c}=T_{7 / 8}\right) / t_{7 / 8}\left(T_{a v g, b o x}=T_{7 / 8}\right)$ is 1.5 or less. This implies that the SECT based on $T_{c}$, measured on a single orange in the central part of a box, provides quite a good representative value for the average SECT of all fruit within the box. This finding is particularly of interest since in experiments only $T_{c}$ is measured in one or a limited amount of fruit in a box, due to the time and cost associated with setting up such measurements.

(a) Average fruit temperature in entire box

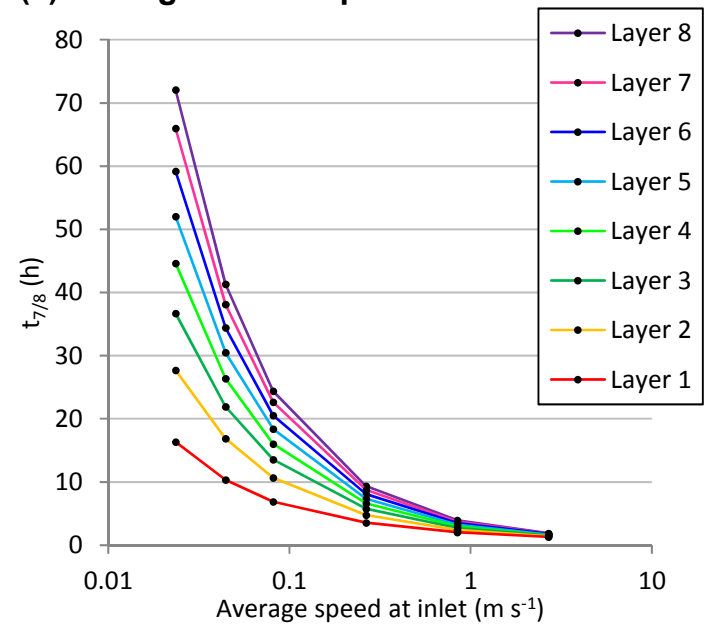

(b) Core temperature of single fruit

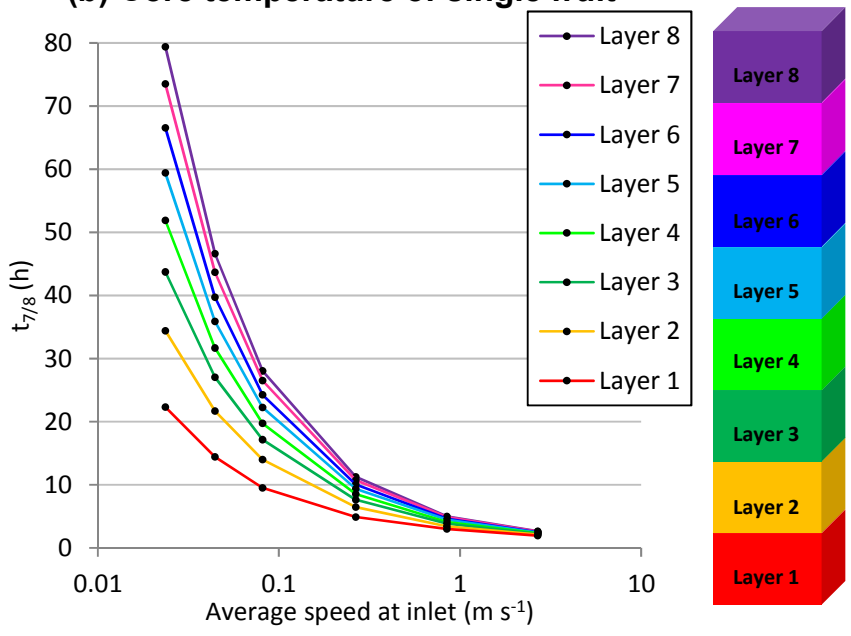

Figure 4. SECT $\left(t_{7 / 8}\right)$ for each layer of boxes as a function of air speed at the inlet (logarithmic scale). The SECT is based on (a) volume-averaged fruit temperature of all fruit in a specific box (thus layer); and (b) the temperature in the core of a single fruit located in the central part of a box. Configuration shown is with no gaps between pallets (base model). 
Defraeye T., Cronjé P., Verboven P., Opara U.L., Nicolai B. (2015), Exploring ambient loading of citrus fruit into reefer containers for cooling during marine transport using computational fluid dynamics, Postharvest Biology and Technology 108, 91-101.

http://dx.doi.org/10.1016/j.postharvbio.2015.06.004

\subsection{Cooling rate and cooling uniformity}

The fruit cooling rate is evaluated from the (volume-averaged) temperatures of the fruit in a box $\left(T_{\text {avg,box }}\right)$ as a function of time, as shown in Figure 5 at high and low air speeds. The SECTs that result from these profiles were already represented in Figure 4a for all evaluated air speeds.

As expected, the cooling rate is strongly dependent on the airflow rate, where much lower SECTs are found for high air speeds, typical for FAC ( $\approx 1$ to $3 \mathrm{~L} \mathrm{~s}^{-1} \mathrm{~kg}^{-1}$, see section 2.2 and Table 1$)$, compared to those characteristic for container cooling $\left(\approx 0.02\right.$ to $0.06 \mathrm{~L} \mathrm{~s}^{-1} \mathrm{~kg}^{-1}$, see section 2.2 and Table 1). Also, the spread between the SECT of different layers is much larger at low speeds whereas at FAC cooling speeds, the different layers cool much more uniformly. Hence container cooling within the context of ambient loading does not only induce slower cooling rates, due to the lower air speeds, but it also results in more heterogeneous cooling between layers of boxes, compared to vertical cooling at FAC airflow rates. This increased heterogeneity is due to the fact that the cooling air increases in temperature along the flow direction more quickly at low speeds, resulting in a smaller air temperature difference between the fruit (surface) and air for the upper boxes, which reduces the energy removal rate here. Such improved cooling uniformity at higher airflow rates was also found by de Castro et al. (de Castro et al., 2005) for FAC, amongst others.

(a) Low speed (at $\Delta \mathrm{P}=1 \mathrm{~Pa})$

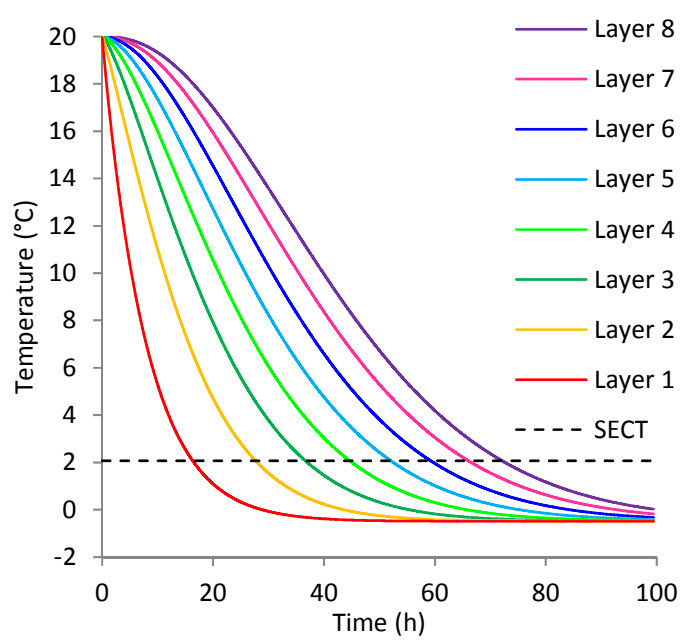

(b) High speed (at $\Delta \mathrm{P}=10000 \mathrm{~Pa})$

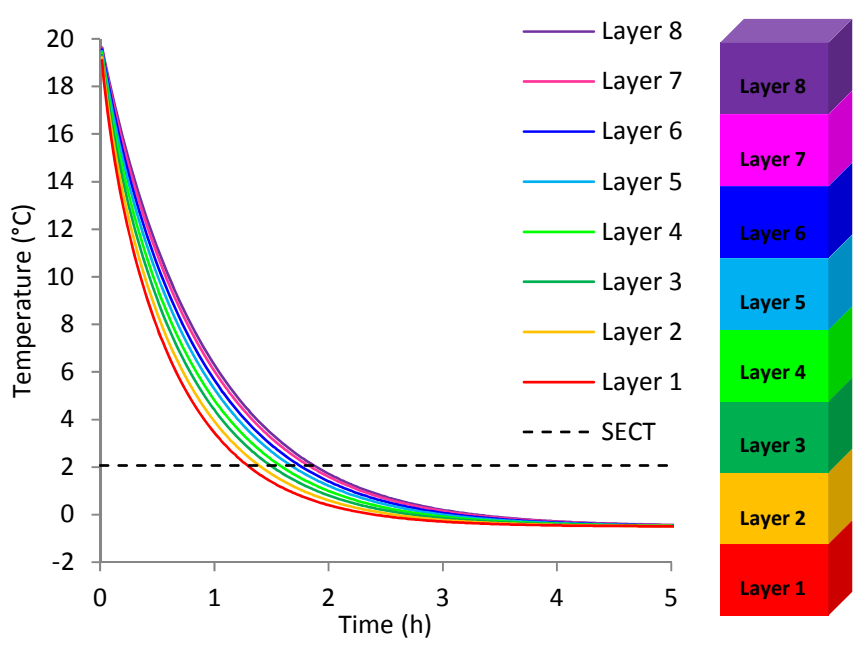


Defraeye T., Cronjé P., Verboven P., Opara U.L., Nicolai B. (2015), Exploring ambient loading of citrus fruit into reefer containers for cooling during marine transport using computational fluid dynamics, Postharvest Biology and Technology 108, 91-101.

http://dx.doi.org/10.1016/j.postharvbio.2015.06.004

Figure 5. Volume-averaged temperature of all fruit in a specific box for each layer of boxes as a function of time for (a) low and (b) high airflow rates. The SECT temperature is also indicated. Configuration shown is with no gaps between pallets (base model).

In addition to the heterogeneity of fruit cooling among individual layers of boxes, the cooling uniformity of individual fruit within a single box is also of interest. Therefore, the spread on the CHTC for all fruit within a single box was determined, in a similar way as Defraeye et al. (Defraeye et al., 2013a), as an alternative to determining the SECT for each individual fruit. To this end, the CHTC of each computational cell on the surface of all oranges within a box was calculated at the start of the simulations $\left(t=0 \mathrm{~s}, T_{w}=20^{\circ} \mathrm{C}\right)$. The relative frequency distribution is shown in Figure 6a-c for each layer at three different flow rates. These CHTCs are scaled with the average CHTC per box ( $\mathrm{CHTC}_{\text {avg }}$ ), so these graphs do not reflect differences in magnitude between $\mathrm{CHTCs}$ of different boxes. Note that this scaling was done as the CHTCs were all defined based on a (constant) approach flow temperature. Preferably, the variation of the CHTC within an individual box should be as small as possible, as well as the variation of the CHTCs between the individual layers, to ensure uniformity in cooling rates between individual fruit. Note that the coefficient of variation of these CHTC distributions for different layers is given in Figure $6 \mathrm{~d}$ as a function of the air speed at the inlet.

At each specific speed, the oranges in each layer of boxes cool approximately with a similar uniformity, except for layer 1, which cools somewhat more uniform than the other layers. Keep in mind though that the cooling rates of all boxes differ (see above in Figure 5). At high speeds, a quite homogeneous distribution is found for each layer. If the speed decreases, this distribution becomes wider and more skewed towards lower CHTCs. In conclusion, higher speeds result in more uniform cooling of individual fruit within a single box, which is similar to what was found with respect to the cooling uniformity between different layers of boxes, discussed above. 
Defraeye T., Cronjé P., Verboven P., Opara U.L., Nicolai B. (2015), Exploring ambient loading of citrus fruit into reefer containers for cooling during marine transport using computational fluid dynamics, Postharvest Biology and Technology 108, 91-101.

http://dx.doi.org/10.1016/j.postharvbio.2015.06.004

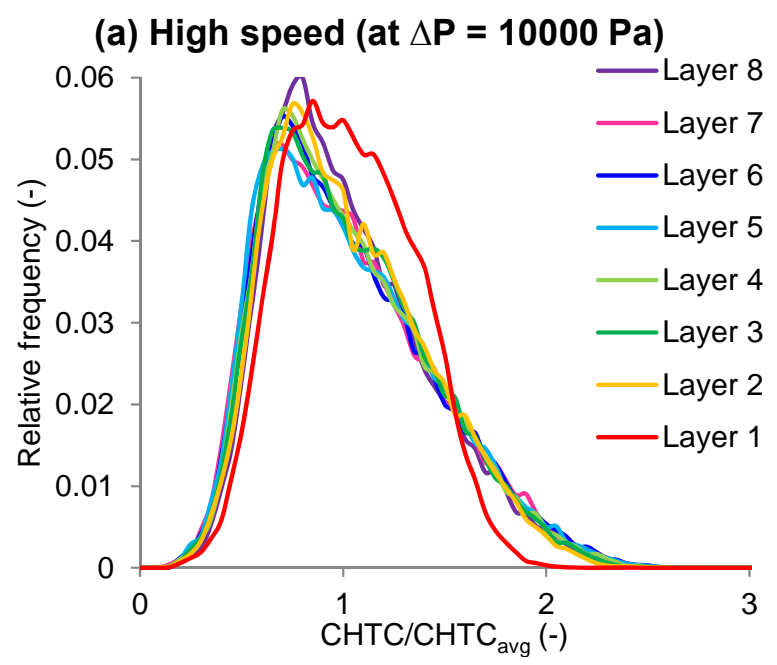

(b) Middle speed (at $\Delta \mathrm{P}=100 \mathrm{~Pa}$ )

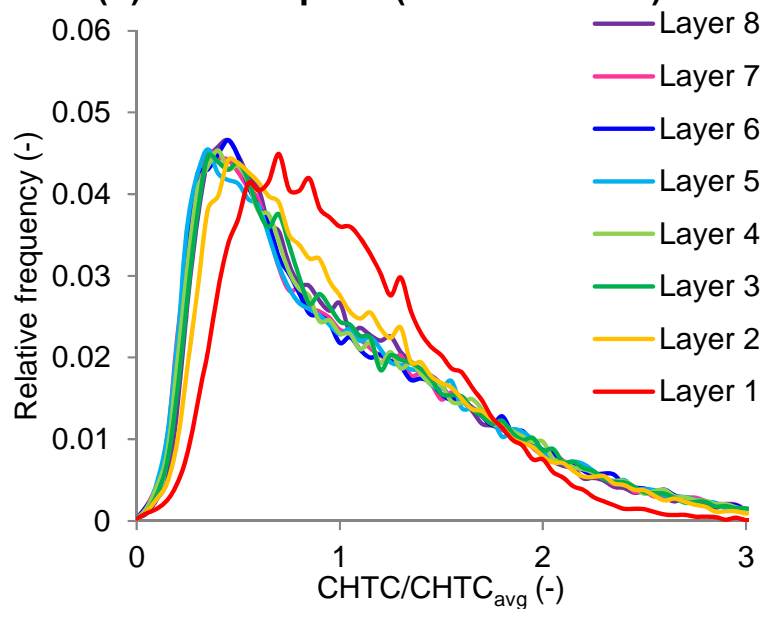

(c) Low speed (at $\Delta \mathrm{P}=1 \mathrm{~Pa}$ )
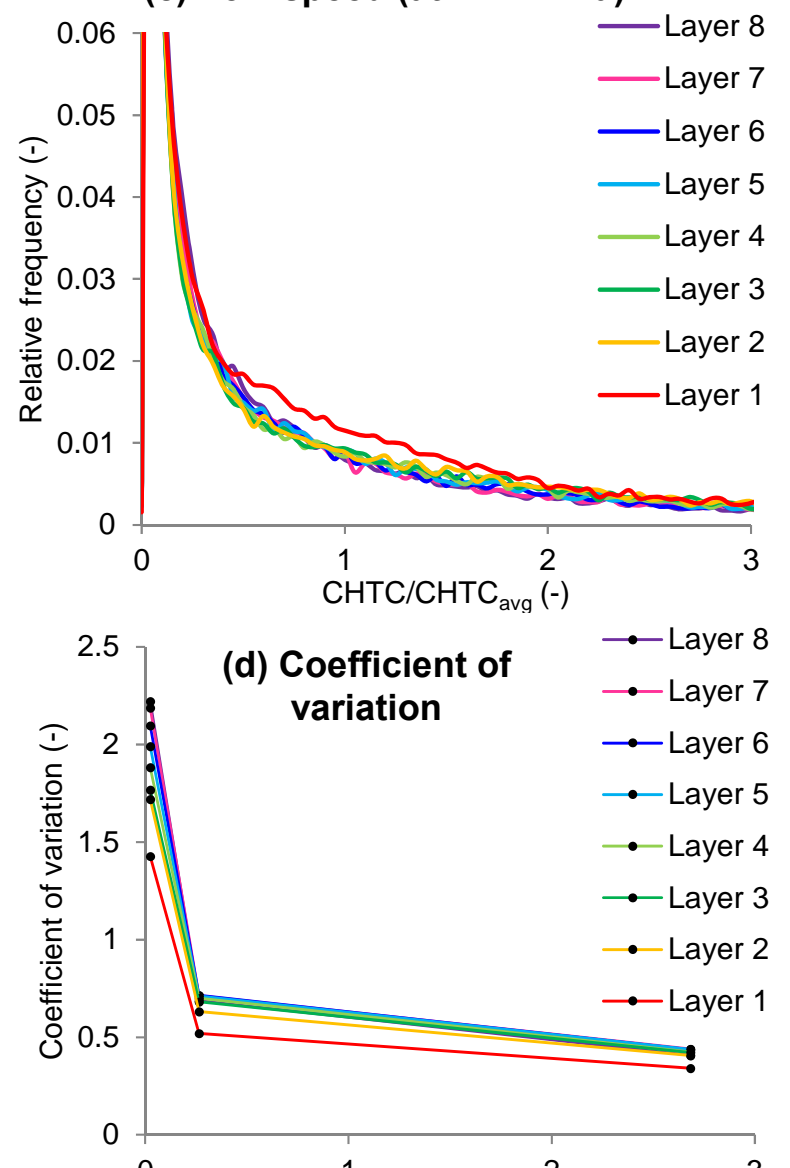
Defraeye T., Cronjé P., Verboven P., Opara U.L., Nicolai B. (2015), Exploring ambient loading of citrus fruit into reefer containers for cooling during marine transport using computational fluid dynamics, Postharvest Biology and Technology 108, 91-101.

http://dx.doi.org/10.1016/j.postharvbio.2015.06.004

Figure 6. Relative frequency distribution of the convective heat transfer coefficient (CHTC) for each layer of boxes, for three different air speeds (a-c). The $\mathrm{CHTCs}$ are scaled with the average $\mathrm{CHTC}$ per box $\left(\mathrm{CHTC}_{\text {avg }}\right)$. Configuration shown is with no gaps between pallets (base model). The coefficient of variation of these CHTC distributions is given in (d) as a function of the air speed at the inlet.

\subsection{Comparison of cooling with vertical and horizontal airflow}

The fruit cooling rates achieved by vertical airflow, which occurs in refrigerated containers, were compared to horizontal airflow cooling over a single pallet, typical for FAC in pre-cooling facilities, in Figure 7 by means of the $\operatorname{SECT}\left(t_{7 / 8}\left(T_{c}=T_{7 / 8}\right)\right)$. The FAC data (for $\left.T_{c}\right)$ were taken from Defraeye et al. (Defraeye et al., 2014), which evaluated the same Supervent box, stacked (horizontally) in three subsequent rows of boxes (row 1 is most upstream) at pressure differences of $100 \mathrm{~Pa}, 1000 \mathrm{~Pa}$ and $10000 \mathrm{~Pa}$. These SECTs are presented in Figure 7 as a function of the flow rate per mass of fruit in the computational model, instead of the average air speed at the inlet since the inlet area of the computational domains differs for both cases, making a comparison based on speeds not meaningful.

The SECTs for horizontal airflow are of similar magnitude as the ones for vertical airflow, but note that the SECTs are dependent on the layer or row that is considered. This similarity is not surprising as the total vent area of the Supervent box in the vertical direction is similar to the one in the horizontal direction (and even slightly larger, Figure 2a): the amount of half-circular vent holes is the same and an additional opening is present at both top and bottom of the box. In addition, the stacking in the computational model for vertical airflow is assumed perfect in this case, i.e., there is no blocking of vent holes, whereas for horizontal flow, some vent holes were blocked (Defraeye et al., 2013a). The first layer of boxes for vertical airflow even cools slightly faster than the first row of boxes for horizontal airflow. Note also that the location of the vent holes is very similar for horizontal and vertical airflow, namely at the edges of the box. Though a general comparison was made here between horizontal and vertical airflow cooling, one has to keep in mind that vertical cooling takes place in refrigerated containers at low airflow rates, whereas horizontal FAC usually occurs at much higher airflow rates. The vertical configuration results in a somewhat higher pressure drop across the stack at a particular flow rate, amongst others due to the 
Defraeye T., Cronjé P., Verboven P., Opara U.L., Nicolai B. (2015), Exploring ambient loading of citrus fruit into reefer containers for cooling during marine transport using computational fluid dynamics, Postharvest Biology and Technology 108, 91-101.

http://dx.doi.org/10.1016/j.postharvbio.2015.06.004

longer pathway that the air needs to follow through the produce-packaging system, thereby requiring more powerful fans to achieve the same flow rates as in the horizontal configuration. This higher flow resistance for the vertical configuration is clear from Figure 7, where lower flow rates are found compared to horizontal flow for the same pressure drop (e.g., at $10000 \mathrm{~Pa}$, highest flow rate).

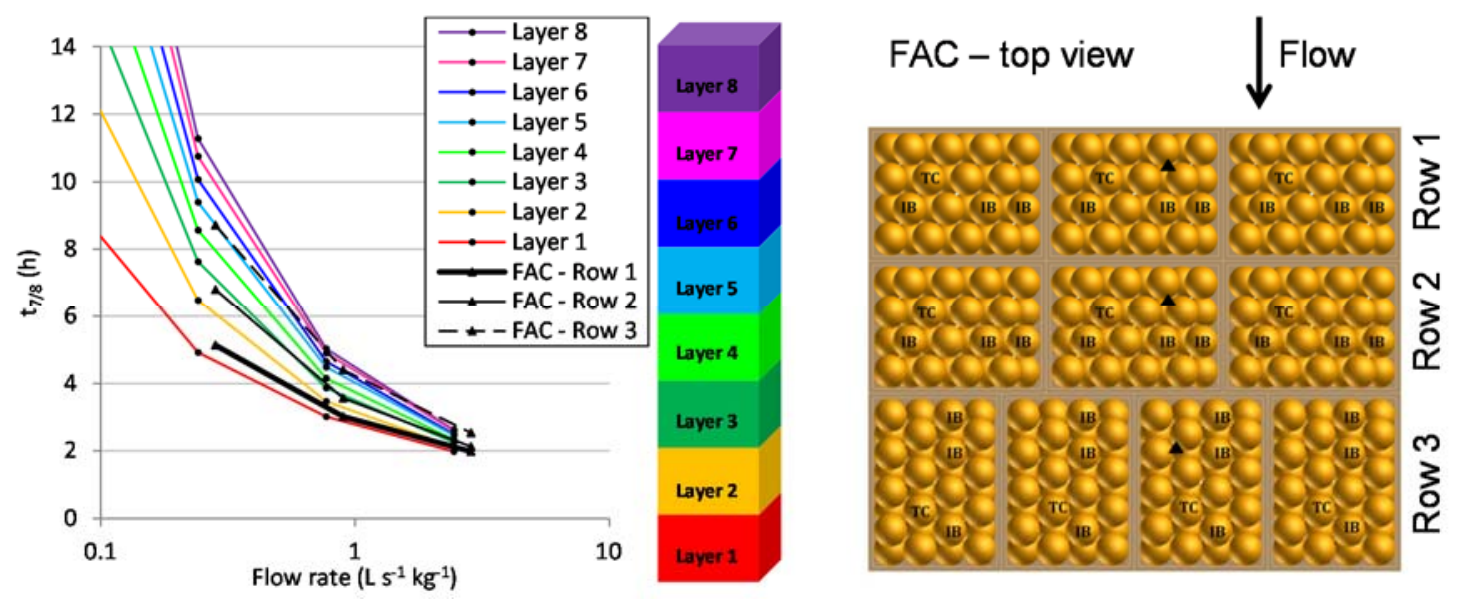

Figure 7. SECT $\left(t_{7 / 8}\right)$ for each layer of boxes as a function of flow rate per mass of fruit (in $\mathrm{L} \mathrm{s}^{-1} \mathrm{~kg}^{-1}$, logarithmic scale) for vertical airflow cooling (data points visible at 100, 1000 and $10000 \mathrm{~Pa}$ ). The SECT is based on the temperature in the core of a single fruit located in the central part of a box. The results for forced-air precooling (FAC, horizontal flow at 100, 1000 and 10000 Pa, see Figure 2) from Defraeye et al. (Defraeye et al., 2014) are also included for three rows of boxes (row 1 is the most upstream). Configuration shown is with no gaps between pallets (base model). On the right, the FAC configuration with indication of the rows is shown.

\subsection{Influence of spacing between pallets}

In a reefer container, gaps between pallets are usually present due to: (1) imperfect (straight) stacking of boxes on the pallet; (2) the additional spacing (tolerance) that is provided over the width of the container to be able to load it; and (3) the fact that the container floor area cannot be entirely covered with standard pallets (Defraeye et al., 2015), where about $9 \%$ remains uncovered in a $12.2 \mathrm{~m}$ (40 feet) container. As such, there will always be an amount of airflow bypass, unless all gaps are closed, which is however not current practice. 
Defraeye T., Cronjé P., Verboven P., Opara U.L., Nicolai B. (2015), Exploring ambient loading of citrus fruit into reefer containers for cooling during marine transport using computational fluid dynamics, Postharvest Biology and Technology 108, 91-101.

http://dx.doi.org/10.1016/j.postharvbio.2015.06.004

The impact of airflow short-circuits, i.e., gaps between pallets, on the cooling rate of fruit within different layers of boxes was evaluated in a rather pragmatic way, namely by modelling gaps between single rows of boxes with three different widths $(6.25,25$ and $100 \mathrm{~mm}$, Figure 3b). These gap widths (for the simplified computational model of one row of boxes) correspond to equivalent gaps between single pallets (i.e., entire pallets consisting of 8 layers of 10 boxes each, Figure 2b) of 10, 40 and $159 \mathrm{~mm}$ respectively (pallet base area for 10 boxes $=1.2 \times 1$ $\left.\mathrm{m}^{2}\right)$. In Figure 8, the SECT $\left(t_{7 / 8}\left(T_{\text {avg,box }}=T_{7 / 8}\right)\right)$ is given for the base model and for all gap widths as a function of the average air speed at the inlet of the computational domain, for three different layers of boxes (Layer 1, 4 and 8). Note that although all computational models are evaluated for the same air speeds, the pressure drop over each model differs, with much lower values when a gap is present. Although this boundary condition implies that the flow rate per meter squared at the inlet is the same, the total flow rate increases with gap width (Table 1). A comparison of different gap widths at the same air speed does not entirely correspond to reality as the working point of the fans will also change if gaps are present, due to the change of the system (resistance) curve of the container's airflow circuit. The aim of the present study was, however, primarily to gain elementary insight in the magnitude of the impact of gaps on the cooling rate.

From Figure 8, the SECT clearly increases with increasing gap width for all air speeds. A complex dependency of the SECT on the gap width and the air speed is found, which differs for each layer of boxes. The large impact of such gaps on the fruit cooling rate stresses the importance of minimising such airflow short-circuits between pallets, since otherwise a large amount of refrigerated air will bypass the produce in this way. The presence of gaps, however, improved cooling uniformity (i.e., differences in SECT) between different layers on the pallet. 
Defraeye T., Cronjé P., Verboven P., Opara U.L., Nicolai B. (2015), Exploring ambient loading of citrus fruit into reefer containers for cooling during marine transport using computational fluid dynamics, Postharvest Biology and Technology 108, 91-101.

http://dx.doi.org/10.1016/j.postharvbio.2015.06.004
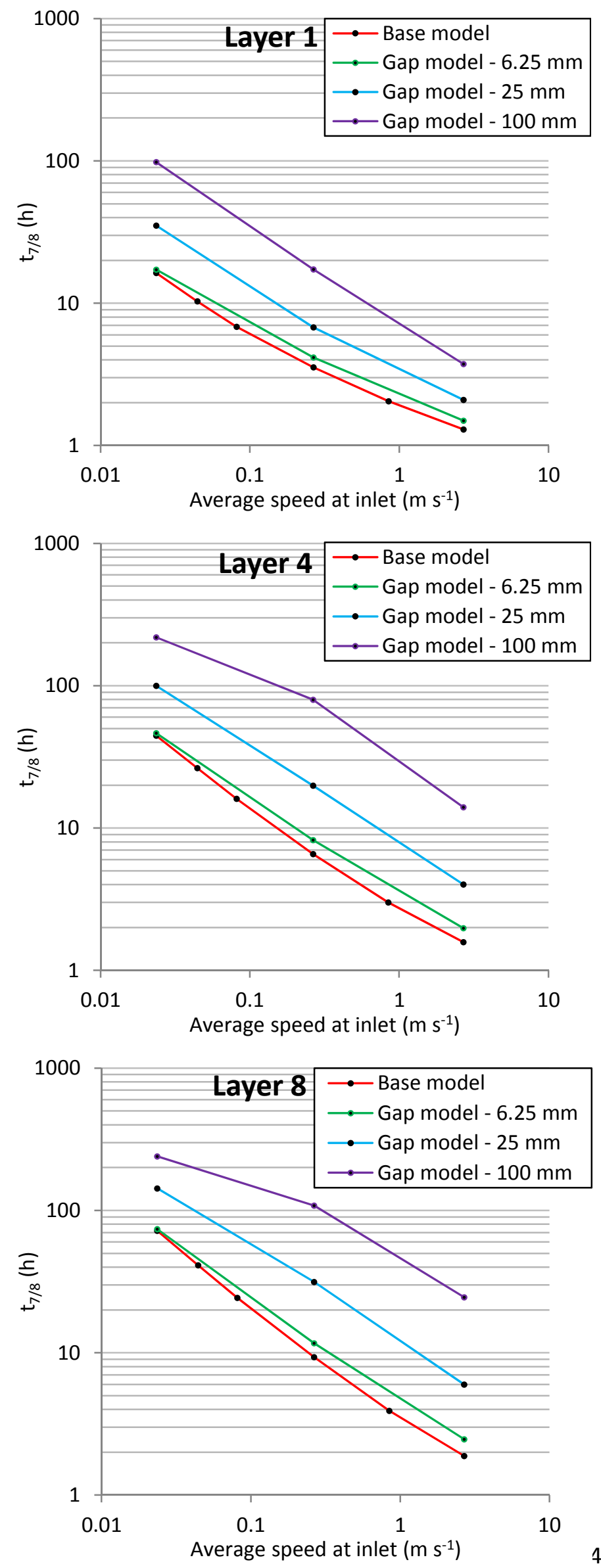
Defraeye T., Cronjé P., Verboven P., Opara U.L., Nicolai B. (2015), Exploring ambient loading of citrus fruit into reefer containers for cooling during marine transport using computational fluid dynamics, Postharvest Biology and Technology 108, 91-101.

http://dx.doi.org/10.1016/j.postharvbio.2015.06.004

Figure 8. SECT $\left(t_{7 / 8}\right)$ for different gap widths as a function of air speed at the inlet (both axis have logarithmic scaling) for three layers of boxes. The SECT is based on the volume-averaged fruit temperature of all fruit in a specific box (thus layer). Configuration shown are with/without gaps between pallets (gap model).

\section{Discussion}

Despite being a promising alternative cold-chain protocol as it avoids pre-cooling of fruit prior to loading in refrigerated containers, ambient loading is very challenging due to the many practical restrictions inherent to the method, amongst others: (1) the airflow rate and installed cooling capacity in a reefer container are limited and are prescribed by the container type; (2) vertical airflow induces a longer pathway for air through the fruit, compared to horizontal pre-cooling over a single pallet; (3) box design and stacking on the pallet are often not optimised for vertical airflow and a wooden pallet base also blocks a significant amount of vent holes; (4) limited accessibility during loading for closing airflow short-circuits between pallets. Below, the limitations of the current computational model are highlighted, the feasibility of ambient loading is discussed in light of the findings of the present study and possible ways forward to optimise the method are given.

\subsection{Computational modelling of container cooling}

To assess the cooling process of fruit within a refrigerated container, CFD was shown to exhibit unique advantages, such as the ability to evaluate the more relevant volume-averaged fruit temperature instead of that in the centre of the fruit but also the cooling of each individual fruit in a box, thus the intra-box heterogeneity. Such heterogeneity within a single box could explain the variation of chilling injury that is normally found within a box after commercial export when applying a cold disinfestation protocol. CFD is thus clearly a valuable tool for evaluation and optimisation of cooling processes of fruit in reefer containers, and nicely complements experimental work.

However, some model simplifications were made in the simulations to limit the computational cost. The most important one is the use of an idealised stacking pattern on the pallet, implying perfect vertical channelling of 
Defraeye T., Cronjé P., Verboven P., Opara U.L., Nicolai B. (2015), Exploring ambient loading of citrus fruit into reefer containers for cooling during marine transport using computational fluid dynamics, Postharvest Biology and Technology 108, 91-101.

http://dx.doi.org/10.1016/j.postharvbio.2015.06.004

airflow since there is no blockage of vent holes by subsequent boxes and by the wooden pallet base (for the first layer of boxes). As such, the reported SECTs are somewhat too optimistic and will differ to some extent from reality. A next step could be to model an entire pallet (Figure $2 b$ ), including short circuits between the pallets, which would however imply a computational grid of over 30 million cells, when the same grid refinement is maintained as in the present study. Modelling an entire container (with 20 pallets) is currently numerically too challenging if the individual fruit are modelled discretely. At this scale, however, the porous medium approach can be applied (Ambaw et al., 2014, 2013b; Nahor et al., 2005; Verboven et al., 2006). Additional full-scale experiments, similar to the one of Defraeye et al. (Defraeye et al., 2015), are underway to complement the simulation results, which will allow to determine realistic SECTs that include actual stacking patterns, operating conditions and gaps between pallets. In a next step, the cooling rate uniformity between different pallets within a single container should be evaluated in detail and optimised, as large heterogeneities between different pallets were recently identified (Defraeye et al., 2015).

\subsection{Feasibility of ambient loading}

For ambient loading to be applicable in practice, the fruit temperature needs to be reduced sufficiently fast so fruit quality and shelf life are not too negatively affected by the longer pre-cooling time in the container, compared to FAC. From the present study, the SECT (at typical container airflow rates, i.e., $0.0214 \mathrm{~L} \mathrm{~s}^{-1} \mathrm{~kg}^{-1}$ in this study) varies between $16 \mathrm{~h}$ for layer 1 to $72 \mathrm{~h}$ for layer 8 for the base model (Figure $4 a$ ). These values are rather low but are for an idealised case which exhibits a somewhat faster cooling rate than in practice. The question remains if these SECTs can actually be obtained with the installed cooling capacity in a refrigerated container. A previous study (Defraeye et al., 2015) calculated that an overall SECT slightly below $5 \mathrm{~d}$ could be obtained theoretically with the cooling capacity of a standard refrigerated container, which is well above the SECTs that are obtained in the present study. For the present idealised case, a fruit can be cooled quite fast in a refrigerated container, as a SECT below 3 days could be obtained. Experimental observations, however, showed that the fruit could not be cooled down fast enough due to the limited amount of energy that was transferred from the fruit to its surrounding environment. As such, the reefer cooling unit was not used to its full capacity, compared to when 
Defraeye T., Cronjé P., Verboven P., Opara U.L., Nicolai B. (2015), Exploring ambient loading of citrus fruit into reefer containers for cooling during marine transport using computational fluid dynamics, Postharvest Biology and Technology 108, 91-101.

http://dx.doi.org/10.1016/j.postharvbio.2015.06.004

heat transfer between fruit and environment would be more enhanced (Defraeye et al., 2015; Jedermann et al., 2014). These findings clearly indicate that improvements to the current practice can be made on the one hand

(e.g., box design, closing of gaps), and that more realistic CFD models should be applied on the other hand. Mimicking a gap between the pallets is a step in this direction (section 3.4) and clearly led to increased SECTs.

\subsection{Optimisation of vertical cooling}

Optimisation of the ambient loading technique or (vertical) cooling of horticultural produce in general is not that straightforward due to the complex interrelations between process parameters (air speed, set air temperature, amount of airflow short-circuits, box design, etc.), which results in multiple trade-offs between process objectives (cooling rate, cooling uniformity within box, pallet or container, chilling injury, shelf life, energy consumption by fans, etc.). Typical examples are how a higher air speed enhances cooling rate and uniformity, but induces more chilling injury and energy consumption; or how gaps between pallets reduce cooling rate, but can enhance cooling uniformity and reduce energy consumption of the fans (reduced pressure drop) but, on the other hand, can also make them run less/more efficient due to a shift of the fan working point. Optimisation of vertical cooling will require the combined use of experimental and numerical techniques in complementary ways. CFD is considered more suitable to assess and quantify cooling rate, uniformity and the performance of different box designs but experiments are indispensable here for CFD model validation. On the other hand, researchers still predominantly rely on experiments to evaluate fruit quality (e.g., chilling injury and shelf life), as accurate, calibrated numerical models for fruit quality evaluation are rather often scarce and strongly cultivar dependent. Detailed experiments are essential here for further fruit quality model development.

Within the context of ambient loading, improving cooling rate and uniformity among individual fruits is currently the primary challenge, in order to achieve a cooling behaviour as close as possible to that of FAC. Achieving cooling uniformity between different individual fruits in a box, pallet or cargo is critical to provide similar fruit quality throughout the entire shipment. Too slow cooling rates are the main reason that ambient loading is currently not applicable for less resilient citrus cultivars. To this end, several improvements compared to current 
Defraeye T., Cronjé P., Verboven P., Opara U.L., Nicolai B. (2015), Exploring ambient loading of citrus fruit into reefer containers for cooling during marine transport using computational fluid dynamics, Postharvest Biology and Technology 108, 91-101.

http://dx.doi.org/10.1016/j.postharvbio.2015.06.004

practice can be made. Box design and stacking on the pallet could be optimised (Figure 2) to provide less obstructions of vent holes by subsequent boxes, leading to a better channelling of the airflow. In principle, the pallet design could also be altered to reduce the large amount of blocking of vent holes by the commonly used wooden pallet base. The performance of more open-porous plastic pallets is currently being explored by the authors but the strength and stability are currently not sufficient yet. In addition, the efficacy of practical methods to reduce the amount of airflow short-circuits between pallets in a refrigerated container is currently being explored by the authors, by means of full-scale container experiments. Finally, also partial pre-cooling of the cargo could be performed using FAC, after which the fruit are loaded in the container to remove the rest of the field heat. In comparison to direct ambient loading, this partial ambient loading strategy however requires additional time and handling inherent to FAC, which removes some logistical advantages of ambient loading.

\section{$\underline{\text { 5. Conclusions }}$}

An alternative to forced-air pre-cooling (FAC) of horticultural produce (citrus fruit) after harvest was explored by means of computational fluid dynamics (CFD): ambient (warm) loading of produce into refrigerated containers for cooling during marine transport. This cold-chain protocol differs in many ways from FAC due to the vertical airflow, low airflow rates and limited installed cooling capacity within the reefer container. By evaluating higher flow rates up to those characteristic for FAC, this study also covers vertical cooling in general. The main perspective was to gain insight in cooling rates and cooling uniformity between individual fruit in a box and between boxes at different heights on a pallet. The main conclusions were the following:

- At low airflow rates (volumetric rate of air movement per mass of product, $\mathrm{L} \mathrm{s}^{-1} \mathrm{~kg}^{-1}$ ), typical for refrigerated containers, the cooling rate was obviously lower but also the heterogeneity in cooling between different layers of boxes (in height) and between individual fruit in a single box was larger, compared to vertical cooling at FAC airflow rates.

- At similar airflow rates, the fruit cooling rates for horizontal and vertical airflow agreed quite well, which was attributed to the box design since it also included vent holes that promoted vertical airflow 
Defraeye T., Cronjé P., Verboven P., Opara U.L., Nicolai B. (2015), Exploring ambient loading of citrus fruit into reefer containers for cooling during marine transport using computational fluid dynamics, Postharvest Biology and Technology 108, 91-101.

http://dx.doi.org/10.1016/j.postharvbio.2015.06.004

pathways. Note, however, that the (vertical) stacking of boxes on the pallet in the computational was more idealised compared to practice.

- The presence of gaps between the pallets invoked significant airflow short-circuiting, which reduced the cooling rate at all box heights on the pallet, but it improved cooling uniformity between the boxes to some extent.

- From the (idealised) computational modelling, a seven-eighths cooling time (SECT) below about $3 \mathrm{~d}$ could be obtained at airflow rates typical for refrigerated containers. Such SECTs however cannot be achieved in practice with the (low) installed cooling capacity in a reefer container, for realistic stacking configurations and with the presence of gaps between pallets.

In this study, an important step was taken towards a more systematic evaluation of this cold-chain protocol for further optimisation, industrial implementation and application for other citrus cultivars and other horticultural products. Strategies for future improvement of the ambient loading protocol include optimising box design and stacking on the pallet specifically for vertical airflow and reducing the airflow short-circuits between the pallets. Though CFD was successfully shown to be a suitable tool to assess fruit cooling behaviour, a synergy between numerical modelling and full-scale experiments is a key focus for further model development.

\section{Acknowledgements}

Thijs Defraeye is a postdoctoral fellow of the Research Foundation - Flanders (FWO) and acknowledges its support. We would like to thank Gerard Grinwis and Johan-Carel Bossman of Maersk Container Industry AS and Richard Lawton from Cambridge Refrigeration Technology for providing us with detailed information on the specifications of refrigerated containers. We would also like to thank Sundays River Citrus Company (Andre Mouton and John Perrold) and Capespan (Keith Roxbury) for fruit and logistical support. U.L. Opara's contribution was supported by the South African Research Chairs Initiative of the Department of Science and Technology and the National Research Foundation. We also want to acknowledge the support of the World Food System Center 
Defraeye T., Cronjé P., Verboven P., Opara U.L., Nicolai B. (2015), Exploring ambient loading of citrus fruit into reefer containers for cooling during marine transport using computational fluid dynamics, Postharvest Biology and Technology 108, 91-101.

http://dx.doi.org/10.1016/j.postharvbio.2015.06.004

(WFSC) of ETH Zürich. This research was carried out in the context of the European COST Action FA1106

('QualiFruit'). 
Defraeye T., Cronjé P., Verboven P., Opara U.L., Nicolai B. (2015), Exploring ambient loading of citrus fruit into reefer containers for cooling during marine transport using computational fluid dynamics, Postharvest Biology and Technology 108, 91-101.

http://dx.doi.org/10.1016/j.postharvbio.2015.06.004

\section{References}

Ambaw, A., Delele, M.A., Defraeye, T., Ho, Q.T., Opara, U.L., Nicolaï, B.M., Verboven, P., 2013a. The use of CFD to characterize and design post-harvest storage facilities: Past, present and future. Comput. Electron. Agric. 93, 184-194.

Ambaw, A., Verboven, P., Defraeye, T., Tijskens, E., Schenk, A., Opara, U.L., Nicolai, B.M., 2013b. Porous medium modeling and parameter sensitivity analysis of 1-MCP distribution in boxes with apple fruit. J. Food Eng. 119, 13-21.

Ambaw, A., Verboven, P., Delele, M.A., Defraeye, T., Tijskens, E., Schenk, A., Nicolai, B.M., 2013c. CFD Modelling of the 3D Spatial and Temporal Distribution of 1-methylcyclopropene in a Fruit Storage Container. Food Bioprocess Technol. 6, 2235-2250.

Ambaw, A., Verboven, P., Delele, M.A., Defraeye, T., Tijskens, E., Schenk, A., Verlinden, B.E., Opara, U.L., Nicolai, B.M., 2014. CFD-based analysis of 1-MCP distribution in commercial cool store rooms: porous medium model application. Food Bioprocess Technol. 7, 1903-1916.

Arduino, G., Carrillo Murillo, D., Parola, F., 2013. Refrigerated container versus bulk: evidence from the banana cold chain. Marit. Policy Manag. 1-18.

ASHRAE, 2010. ASHRAE Handbook - Refrigeration: systems and applications (SI edition). Atlanta.

Brosnan, T., Sun, D., 2001. Precooling techniques and applications for horticultural products - a review. Int. J. Refrig. 24, 154-170.

Carpenter, J., Bloem, S., Hofmeyr, H., 2007. Area-wide control tactics for the false codling moth Thaumatotibia leucotreta in South Africa: a potential invasive species, in: M.J.B. Vreysen, A.S. Robinson, J.H. (Ed.), AreaWide Control of Insect Pests. Springer, Dordrecht, pp. 351-359.

CGA, 2013. Citrus Growers Association of Southern Africa: Key industry statistics for citrus growers 2013.

De Castro, L.R., Vigneault, C., Cortez, L.A.B., 2005. Cooling performance of horticultural produce in containers with peripheral openings. Postharvest Biol. Technol. 38, 254-261.

Defraeye, T., Blocken, B., Carmeliet, J., 2010. CFD analysis of convective heat transfer at the surfaces of a cube immersed in a turbulent boundary layer. Int. J. Heat Mass Transf. 53, 297-308.

Defraeye, T., Herremans, E., Verboven, P., Carmeliet, J., Nicolai, B., 2012. Convective heat and mass exchange at surfaces of horticultural products: A microscale CFD modelling approach. Agric. For. Meteorol. 162-163, 7184.

Defraeye, T., Lambrecht, R., Ambaw, A., Delele, M.A., Opara, U.L., Cronjé, P., Verboven, P., Nicolai, B., $2013 a$. Forced-convective cooling of citrus fruit: Package design. J. Food Eng. 118, 8-18.

Defraeye, T., Lambrecht, R., Delele, M.A., Ambaw, A., Opara, U.L., Cronjé, P., Verboven, P., Nicolai, B., 2014. Forced-convective cooling of citrus fruit: Cooling conditions and energy consumption in relation to package design. J. Food Eng. 121, 118-127. 
Defraeye T., Cronjé P., Verboven P., Opara U.L., Nicolai B. (2015), Exploring ambient loading of citrus fruit into reefer containers for cooling during marine transport using computational fluid dynamics, Postharvest Biology and Technology 108, 91-101.

http://dx.doi.org/10.1016/j.postharvbio.2015.06.004

Defraeye, T., Verboven, P., Nicolai, B., 2013b. CFD modelling of flow and scalar exchange of spherical food products: Turbulence and boundary-layer modelling. J. Food Eng. 114, 495-504.

Defraeye, T., Verboven, P., Opara, U.L., Nicolai, B., Cronjé, P., 2015. Feasibility of ambient loading of citrus fruit into reefers for cooling during marine transport. Submitt. (in Rev.

Dehghannya, J., Ngadi, M., Vigneault, C., 2010. Mathematical modeling procedures for airflow, heat and mass transfer during forced convection cooling of produce: A review. Food Eng. Rev. 2, 227-243.

Dehghannya, J., Ngadi, M., Vigneault, C., 2011. Mathematical modeling of airflow and heat transfer during forced convection cooling of produce considering various package vent areas. Food Control 22, 1393-1399.

Dehghannya, J., Ngadi, M., Vigneault, C., 2012. Transport phenomena modelling during produce cooling for optimal package design: Thermal sensitivity analysis. Biosyst. Eng. 111, 315-324.

Delele, M.A., Ngcobo, M.E.K., Getahun, S.T., Chen, L., Mellmann, J., Opara, U.L., 2013a. Studying airflow and heat transfer characteristics of a horticultural produce packaging system using a 3-D CFD model. Part II: Effect of package design. Postharvest Biol. Technol. 86, 546-555.

Delele, M.A., Ngcobo, M.E.K., Getahun, S.T., Chen, L., Mellmann, J., Opara, U.L., 2013b. Studying airflow and heat transfer characteristics of a horticultural produce packaging system using a 3-D CFD model. Part I: Model development and validation. Postharvest Biol. Technol. 86, 536-545.

Delele, M.A., Schenk, A., Tijskens, E., Ramon, H., Nicolaï, B.M., Verboven, P., 2009. Optimization of the humidification of cold stores by pressurized water atomizers based on a multiscale CFD model. J. Food Eng. 91, 228-239.

Delele, M.A., Tijskens, E., Atalay, Y.T., Ho, Q.T., Ramon, H., Nicolaï, B.M., Verboven, P., 2008. Combined discrete element and CFD modelling of airflow through random stacking of horticultural products in vented boxes. J. Food Eng. 89, 33-41.

Ferrua, M.J., Singh, R.P., 2009a. Design guidelines for the forced-air cooling process of strawberries. Int. J. Refrig. 32, 1932-1943.

Ferrua, M.J., Singh, R.P., 2009b. Modeling the forced-air cooling process of fresh strawberry packages, Part II: Experimental validation of the flow model. Int. J. Refrig. 32, 349-358.

Ferrua, M.J., Singh, R.P., 2011. Improved airflow method and packaging system for forced-air cooling of strawberries. Int. J. Refrig. 34, 1162-1173.

Fitzgerald, W.B., Howitt, O.J. a., Smith, I.J., Hume, A., 2011. Energy use of integral refrigerated containers in maritime transportation. Energy Policy 39, 1885-1896.

Franke, J., Hellsten, A., Schlünzen, H., Carissimo, B., 2007. Best practice guideline for the CFD simulation of flows in the urban environment. Hamburg.

Fraser, H.W., Eng, P., 1998. Factsheet: Tunnel forced-air coolers for fresh fruits \& vegetables.

GDV, 2014. Gesamtverband der Deutschen Versicherungswirtschaft : Container Handbook. 
Defraeye T., Cronjé P., Verboven P., Opara U.L., Nicolai B. (2015), Exploring ambient loading of citrus fruit into reefer containers for cooling during marine transport using computational fluid dynamics, Postharvest Biology and Technology 108, 91-101.

http://dx.doi.org/10.1016/j.postharvbio.2015.06.004

Gowda, B.S., Narasimham, G.S.V.L., Krishna Murthy, M.V., 1997. Forced-air precooling of spherical foods in bulk: A parametric study. Int. J. Heat Fluid Flow 18, 613-624.

Gustavsson, J., Cederberg, C., Sonesson, U., van Otterdijk, R., Meybeck, A., 2011. Global food losses and food wastes - extent, causes and prevention (www.fao.org). Rome, Italy.

Heap, R.D., 2006. Cold chain performance issues now and in the future, in: Innovative Equipment and Systems for Comfort \& Food Preservation. Auckland, pp. 1-13.

Hoang, M.H., Laguerre, O., Moureh, J., Flick, D., 2012. Heat transfer modelling in a ventilated cavity loaded with food product: Application to a refrigerated vehicle. J. Food Eng. 113, 389-398.

IIR, 2009. 5th Informatory Note on Refrigeration and Food: The role of refrigeration in worldwide nutrition (www.iifiir.org).

James, S.J., James, C., Evans, J. a., 2006. Modelling of food transportation systems - a review. Int. J. Refrig. 29, 947-957.

Jedermann, R., Geyer, M., Praeger, U., Lang, W., 2013. Sea transport of bananas in containers - Parameter identification for a temperature model. J. Food Eng. 115, 330-338.

Jedermann, R., Praeger, U., Geyer, M., Lang, W., 2014. Remote quality monitoring in the banana chain. Philos. Trans. R. Soc. A 372, 20130303.

Jiménez-Ariza, T., Correa, E.C., Diezma, B., Silveira, A.C., Zócalo, P., Arranz, F.J., Moya-González, A., Garrido-Izard, M., Barreiro, P., Ruiz-Altisent, M., 2014. The phase space as a new representation of the dynamical behaviour of temperature and enthalpy in a reefer monitored with a multidistributed sensors network. Food Bioprocess Technol. 7, 1793-1806.

Kondjoyan, A., 2006. A review on surface heat and mass transfer coefficients during air chilling and storage of food products. Int. J. Refrig. 29, 863-875.

Menter, F.R., 1994. Two-equation eddy-viscosity turbulence models for engineering applications. AIAA J. 32, 1598-1605.

Moureh, J., Flick, D., 2004. Airflow pattern and temperature distribution in a typical refrigerated truck configuration loaded with pallets. Int. J. Refrig. 27, 464-474.

Moureh, J., Menia, N., Flick, D., 2002. Numerical and experimental study of airflow in a typical refrigerated truck configuration loaded with pallets. Comput. Electron. Agric. 34, 25-42.

Moureh, J., Tapsoba, S., Derens, E., Flick, D., 2009. Air velocity characteristics within vented pallets loaded in a refrigerated vehicle with and without air ducts. Int. J. Refrig. 32, 220-234.

Nahor, H.B., Hoang, M.L., Verboven, P., Baelmans, M., Nicolaï, B.M., 2005. CFD model of the airflow, heat and mass transfer in cool stores. Int. J. Refrig. 28, 368-380.

Norton, T., Sun, D.-W., 2006. Computational fluid dynamics (CFD) - an effective and efficient design and analysis tool for the food industry: A review. Trends Food Sci. Technol. 17, 600-620. 
Defraeye T., Cronjé P., Verboven P., Opara U.L., Nicolai B. (2015), Exploring ambient loading of citrus fruit into reefer containers for cooling during marine transport using computational fluid dynamics, Postharvest Biology and Technology 108, 91-101.

http://dx.doi.org/10.1016/i.postharvbio.2015.06.004

Norton, T., Tiwari, B., Sun, D.-W., 2013. Computational fluid dynamics in the design and analysis of thermal processes: a review of recent advances. Crit. Rev. Food Sci. Nutr. 53, 251-275.

Roache, P.J., 1994. Perspective: a method for uniform reporting of grid refinement studies. J. Fluids Eng. 116, 405-413.

Robertson, G.L., 2013. Food Packaging: Principles and Practice, Third. ed. Taylor \& Francis Group LLC, Boca-Raton.

Rodríguez-Bermejo, J., Barreiro, P., Robla, J.I., Ruiz-García, L., 2007. Thermal study of a transport container. J. Food Eng. 80, 517-527.

Smale, N.J., Moureh, J., Cortella, G., 2006. A review of numerical models of airflow in refrigerated food applications. Int. J. Refrig. 29, 911-930.

Tanner, D.J., Amos, N.D., 2003. Temperature variability during shipments of fresh produce. Acta Hortic. 599, 193203.

Tapsoba, M., Moureh, J., Flick, D., 2006. Airflow patterns in an enclosure loaded with slotted pallets. Int. J. Refrig. 29, 899-910.

Tapsoba, M., Moureh, J., Flick, D., 2007. Airflow patterns in a slot-ventilated enclosure partially loaded with empty slotted boxes. Int. J. Heat Fluid Flow 28, 963-977.

Thompson, A.K., 2003. Fruit and Vegetables - Harvesting, Handling and Storage, First. ed. Blackwell Publishing Ltd., Oxford.

Thompson, J.F., 2004. Pre-cooling and storage facilities, in: USDA (Ed.), USDA Agriculture Handbook Number 66: The Commercial Storage of Fruits, Vegetables, and Florist and Nursery Stocks. USDA, pp. 1-10.

Thompson, J.F., Mitchell, F.G., Rumsey, R.T., Kasmire, R.F., Crisosto, C.H., 2008. Commercial cooling of fruit, vegetables and flowers. University of California, California.

Verboven, P., Flick, D., Nicolaï, B.M., Alvarez, G., 2006. Modelling transport phenomena in refrigerated food bulks, packages and stacks: basics and advances. Int. J. Refrig. 29, 985-997.

White, I.M., Elson, M.M., 2004. Fruit Flies of Economic Significance: Their Identification and Bionomics. CABI.

Xia, B., Sun, D.-W., 2002. Applications of computational fluid dynamics (CFD) in the food industry: a review. Comput. Electron. Agric. 34, 5-24.

Zou, Q., Opara, U.L., McKibbin, R., 2006a. A CFD modeling system for airflow and heat transfer in ventilated packaging for fresh foods: I. Initial analysis and development of mathematical models. J. Food Eng. 77, 10371047.

Zou, Q., Opara, U.L., McKibbin, R., 2006b. A CFD modeling system for airflow and heat transfer in ventilated packaging for fresh foods: II. Computational solution, software development, and model testing. J. Food Eng. 77, 1048-1058. 